\title{
Effects of two inhaled corticosteroid/long-acting beta-agonist combinations on small-airway dysfunction in mild asthmatics measured by impulse oscillometry
}

\author{
This article was published in the following Dove Press journal: \\ Journal of Asthma and Allergy \\ 2 August 2013 \\ Number of times this article has been viewed
}

\section{Bill Diong' \\ Kshitiz Singh ${ }^{2}$ \\ Rogelio Menendez ${ }^{3}$}

'School of Engineering, Southern Polytechnic State University, Marietta, GA, USA; ${ }^{2}$ College of Science and Engineering, Texas Christian University, Fort Worth, TX, USA;

${ }^{3}$ Allergy and Asthma Research Center of El Paso, El Paso, TX, USA
Correspondence: Bill Diong

School of Engineering, Southern

Polytechnic State University,

I I 00 South Marietta Parkway,

Marietta, GA 30060, USA

$\mathrm{Tel}+\mathrm{I} 6789155574$

$\mathrm{Fax}+\mathrm{I} 6789155527$

Email bdiong@spsu.edu
Background: We previously showed that the long-acting beta agonist (LABA) salmeterol as inhalation powder or metered-dose inhaler improves lung-function parameters assessed by impulse oscillometry (IOS) in 2- to 5-year-old children with reversible-airway disease within 15 minutes.

Objective: We studied 12- to 45-year-olds with mild persistent asthma in order to compare the onset and extent of peripheral airway effects following the first dose and after 4 weeks dosing with two inhaled corticosteroid (ICS)/LABA combinations: fluticasone propionate/salmeterol 115/21 and budesonide/formoterol 160/4.5.

Methods: Thirty subjects with mild persistent asthma using only an as-needed short-acting beta-agonist (albuterol) who had at least a $40 \%$ change in integrated low-frequency reactance postalbuterol were selected and randomized to receive either fluticasone propionate/salmeterol or budesonide/formoterol (15 subjects each). We collected three to six IOS replicates at baseline, at 5, 20, 40,60, 120, and 240 minutes postdose at randomization, and after 4 weeks of twice-daily dosing. Blinded investigators calculated IOS frequency-dependent resistance and reactance (R5-R20 and $A X)$, indicative of small-airway dysfunction, and also estimated the peripheral airway resistance $\left(R_{p}\right)$ and peripheral airway compliance $\left(C_{p}\right)$, using a respiratoryimpedance model.

Results: At randomization visits, onset of action was detected as early as 5 minutes ( $t$-test, $P<0.05$ ) after fluticasone propionate/salmeterol by $C_{p}$, and within 5 minutes after budesonide/ formoterol by R5-R20, $A X, R_{p}$, and $C_{p}$. However, after 4 weeks of dosing, only $R_{p}$ was significantly different (from 60 to 120 minutes) after fluticasone propionate/salmeterol, while R5-R20, $A X$, $R_{p}$, and $C_{p}$ were not significantly different within 240 minutes after budesonide/formoterol.

Conclusion: These two ICS/LABA combinations initially improved the peripheral airway function of 12- to 45-year-old asthmatics significantly in about 5 minutes or less, as measured by R5-R20, $A X, R_{p}$, and/or $C_{p}$. After regular dosing for 4 weeks, pre- to postdose differences in these parameters had diminished significantly due to improved predose status of peripheral airways. Single dosing with ICS/LABA combinations in mild persistent asthma improves small-airway function, and the effect is maintained over a 12-hour interval by regular use for 4 weeks.

Keywords: asthma, ICS/LABA combination, impulse oscillometry parameters, lung-model parameters, peripheral airway resistance, peripheral airway compliance

\section{Introduction}

Previous work has revealed a heretofore-unrecognized early effect, ie, in under 15 minutes, of Serevent (salmeterol xinafoate) from a Diskus (inhalation powder) and 
a metered-dose inhaler (MDI) in 2- to 5-year-old children with reversible airflow obstruction, assessed by forced oscillation (IOS). ${ }^{1}$ They had been selected for that study based on demonstrated brisk response to the short-acting beta agonist (SABA) albuterol at screening. Statistically significant changes in airway mechanics were evident at 5 minutes, augmenting over the subsequent 55 minutes, and sustained for the next 8 hours, based on IOS measurements at 5, 30, 60, 120, 240 , and 480 minutes after drug administration. The change was more prominent with Serevent MDI at 5 and 30 minutes in small airways, while that with Serevent Diskus was more prominent in large airways at these time points. While such rapid onset of action is comparable to reports of formoterol onset of action in adults, ${ }^{2}$ it has not been shown that similar early action of salmeterol can be detected by IOS in older children and adults. Moreover, whether and how salmeterol differs from formoterol in terms of central and peripheral airway effects are as yet unanswered questions.

The present study's objectives were to obtain IOS parameters, and also to estimate lung-component properties that reflect small-airway dysfunction (both resistive and elastic components), at baseline and after a single dose in order to compare the onset of drug action. We hypothesized that measurements using current IOS hardware and software along with recently implemented augmentation of measurement techniques, ie, lung model-parameter estimation, would be sensitive enough to detect an early response to Advair hydrofluoroalkane (HFA) MDI (fluticasone propionate/salmeterol $115 / 21$ ) and provide evidence of improved small-airway mechanics at time points comparable to those for Symbicort pressurized metered-dose inhaler (pMDI; budesonide/ formoterol 160/4.5). Furthermore, we asked to what extent either or both inhaled corticosteroid (ICS)/long-acting beta agonist (LABA) combinations would still produce early and significant responses after 4 weeks of dosing, since a persistent beneficial effect on small-airway dysfunction would support the earlier and regular use of these agents in patients with mild persistent asthma. ${ }^{3}$

\section{Methods}

\section{Protocol}

The patients were 12-45 years old with mild persistent asthma as defined by Global Initiative on Asthma/National Institutes of Health guidelines. They were recruited either from the clinic population of the Asthma and Allergy Center of El Paso or through advertising at area colleges. They had to have had at least a 1-year history of asthma requiring SABA (albuterol) as needed, with the addition of short courses of inhaled corticosteroids or oral corticosteroids in the preceding year. Subjects with respiratory infections within the prior 6 weeks, and those using inhaled and/or systemic corticosteroids or leukotriene antagonists within the previous month were excluded, as were those maintained on controllers for $>6$ months in the prior year. Other excluded medications included LABA or oral antihistamines within 24 hours of each visit. At screening, subjects were assessed by routine IOS measures (three to four replicates) at baseline and 20 minutes after SABA HFA pMDI (up to six inhalations). Those who manifested $>40 \%$ decrease in IOS frequencydependent reactance $(A X)$ were enrolled and scheduled for randomization (to Advair or Symbicort) within 1-7 days. On visit 2, two puffs of the study drug were administered and IOS measurements performed, after which subjects were given open-label supplies of either drug and instructed to inhale two puffs twice a day for 4 weeks. To assure $>80 \%$ compliance with dosing, subjects were phoned every week, and their drug canisters weighed. Finally, on visit 3, all measurements undertaken on visit 2 were repeated. This study was conducted in accordance with the amended Declaration of Helsinki, and the protocol was approved by the Chesapeake IRB (Pro00002852) in June 2009; its ClinicalTrials.gov identifier is NCT00867737.

On visits 2 and 3, a review of recent medical history and measurement of vital signs were performed. Extended baseline IOS measurements (six replicates) were followed by dosing and serial IOS measurements over 240 minutes. Heart rate and respiratory rate were recorded at 5, 20, 40, 60,120 , and 240 minutes; immediately after each of these recordings, postdose IOS measurements (three replicates each) were performed. For safety and reproducibility, drugs were administered under supervision and subjects observed while gargling immediately postdose.

Outcome measures (at each postdose time point) included:

- $\quad$ IOS measures R5-R20 and $A X$

- model-derived estimates of large and small airways' resistance and compliance.

The available IOS measures included $A X$ and total respiratory system resistance $R$ and reactance $X$ at $3,5,10,15$, 20, and $25 \mathrm{~Hz}(\mathrm{R} 3, \ldots \mathrm{R} 25 ; \mathrm{X} 3, \ldots \mathrm{X} 25)$, which yielded R5-R20. In addition, the twelve frequency-dependent $R$ and $\mathrm{X}$ measures were fitted to an equivalent electrical model (analog) of the respiratory system to derive estimates of its constituent resistance, inertance, and compliance values.

Paired $t$-tests compared each patient's baseline IOS $A X$ and R5-R20 parameters, and each patient's baseline 
large- and small-airway resistance and compliance estimates, at visits 2 and 3, with the same at each postdose time point. Statistical significance represented by $P<0.05$ was used to determine onset of action.

\section{Demographics}

Of 96 candidates screened, 31 were enrolled based on the aforementioned criteria; informed written consent was obtained from all patients for the treatment/testing and for their medical data to be used in this study. However, one subject withdrew, very early, so only 30 subjects completed the study. Their demographics were: 15 male, 15 female, ages $12-45(26.5 \pm 11.5)$ years, height 142-181 (163.0 \pm 9.6$) \mathrm{cm}$, and weight 32.5-150.2 (82.2 \pm 23.2$) \mathrm{kg}$. Advair or Symbicort was randomly administered to 15 subjects each; the specific drug assignment was not revealed to the data analysts until they completed all IOS calculations and model-parameter estimations.

\section{Data analysis and modeling}

The IOS parameters R5-R20 and $A X$, representing lowfrequency dependence of resistance ${ }^{4}$ and integrated low-frequency reactance area, ${ }^{5}$ respectively, were obtained directly from the test readouts of all the 30 subjects; no adverse events occurred, and all data were of sufficient quality and consistency. With a little more effort, the respiratory system's aggregated small-airway resistance $\left(R_{p}\right)$ and small-airway compliance $\left(C_{p}\right)$ were estimated assuming the augmented RIC (aRIC) model, ${ }^{6}$ which also includes the large-airway resistance $(R)$ and inertance $(I)$, and extrathoracic upperairway compliance $\left(C_{e}\right)$; the estimates being those values producing the best least-squares fit to the given $(\mathrm{R} 3, \ldots \mathrm{R} 25$; $\mathrm{X} 3, \ldots \mathrm{X} 25) .{ }^{6}$ Then, paired $t$-tests were applied to compare the IOS parameters as grouped by administered drug, visit number, and time point. This same procedure was applied to the aRIC model estimates of $R_{p}$ and $C_{p}$.

\section{Results}

The mean values of R5-R20 and $A X$ and of $R_{p}$, and $C_{p}$ at baseline and each postdose time point are shown in Table 1. The results of paired $t$-tests comparing R5-R20 and $A X$ at each postdose time point to baseline values are plotted in Figures 1 and 2, and those of comparing $R_{p}$ and $C_{p}$ at each time point to baseline values in Figures 3 and 4.

For the randomization visits, onset of action was detected from R5-R20 and $A X(P<0.05)$ between 5 and 20 minutes after Advair and by 5 minutes after Symbicort, the effects being uniformly sustained through 240 minutes by both medications. During the final visits, onset of action was detected from $A X$ between 5 and 20 minutes after Advair and was sustained up to 240 minutes, whereas no onset of action could be detected post-Symbicort over 240 minutes.

From the model estimates, onset of action during the randomization visits was detected by $C_{p}$ between 5 and 20 minutes after Advair $(P<0.05)$, and by 5 minutes after Symbicort (based on $C_{p}$ and also $R_{p}, P<0.05$ ), the effects being uniformly sustained through 240 minutes by both medications. During the final visits, onset of action was detected from $R_{p}$ between 40 and 60 minutes after Advair, and this was sustained to between 120 and 240 minutes, whereas no onset of action could be detected from $C_{p}$ and $R_{p}$ post-Symbicort over 240 minutes.

\section{Discussion}

We had hypothesized that Advair HFA MDI 115/21 would produce an earlier than expected response in asthmatic

Table I Mean values of impulse oscillometry system frequency-dependent resistance (R5-R20; $\mathrm{cmH}_{2} \mathrm{O} / \mathrm{L} / \mathrm{s}$ ) and reactance $A X$ $\left(\mathrm{cmH}_{2} \mathrm{O} / \mathrm{L}\right)$, peripheral airway resistance $\left(R_{p} ; \mathrm{cmH}_{2} \mathrm{O} / \mathrm{L} / \mathrm{s}\right)$, and peripheral airway compliance $\left(\mathrm{C}_{p} ; \mathrm{L} / \mathrm{cmH}_{2} \mathrm{O}\right)$ at baseline $(\mathrm{BL})$ and each time point after administration of Advair or Symbicort during the randomization and final visits

\begin{tabular}{|c|c|c|c|c|c|c|c|c|c|c|c|c|c|c|}
\hline & \multicolumn{7}{|c|}{ Advair (randomization visit) } & \multicolumn{7}{|c|}{ Symbicort (randomization visit) } \\
\hline & BL & 5 & 20 & 40 & 60 & 120 & 240 & BL & 5 & 20 & 40 & 60 & 120 & 240 \\
\hline R5-R20 & 0.204 & 0.159 & 0.126 & 0.114 & 0.113 & 0.127 & 0.129 & 0.259 & 0.113 & 0.108 & 0.112 & 0.097 & 0.096 & 0.098 \\
\hline$A X$ & 1.526 & 1.122 & 0.774 & 0.692 & 0.660 & 0.759 & 0.763 & 2.332 & 0.643 & 0.597 & 0.663 & 0.554 & 0.537 & 0.536 \\
\hline$R_{p}$ & 0.547 & 0.503 & 0.423 & 0.425 & 0.396 & 0.409 & 0.394 & 0.689 & 0.397 & 0.380 & 0.403 & 0.372 & 0.356 & 0.359 \\
\hline \multirow[t]{3}{*}{$C_{p}$} & 0.084 & 0.114 & 0.138 & 0.141 & 0.146 & 0.135 & 0.139 & 0.067 & 0.134 & 0.161 & 0.143 & 0.152 & 0.162 & 0.163 \\
\hline & \multicolumn{7}{|c|}{ Advair (final visit) } & \multicolumn{7}{|c|}{ Symbicort (final visit) } \\
\hline & BL & 5 & 20 & 40 & 60 & 120 & 240 & BL & 5 & 20 & 40 & 60 & 120 & 240 \\
\hline R5-R20 & 0.164 & 0.135 & 0.119 & 0.111 & 0.118 & 0.118 & 0.123 & 0.127 & 0.101 & 0.094 & 0.099 & 0.099 & 0.096 & 0.096 \\
\hline$A X$ & I.I7I & $0.84 I$ & 0.663 & 0.613 & 0.594 & 0.606 & 0.687 & 0.833 & $0.57 \mid$ & 0.551 & 0.554 & 0.545 & 0.526 & 0.529 \\
\hline$R_{p}$ & 0.472 & 0.429 & 0.406 & 0.387 & 0.372 & 0.361 & 0.405 & 0.426 & 0.406 & 0.399 & 0.385 & 0.370 & 0.350 & 0.364 \\
\hline$C_{p}$ & 0.115 & 0.130 & 0.141 & 0.150 & 0.147 & 0.147 & 0.139 & 0.136 & 0.166 & 0.165 & 0.161 & 0.163 & 0.168 & 0.169 \\
\hline
\end{tabular}



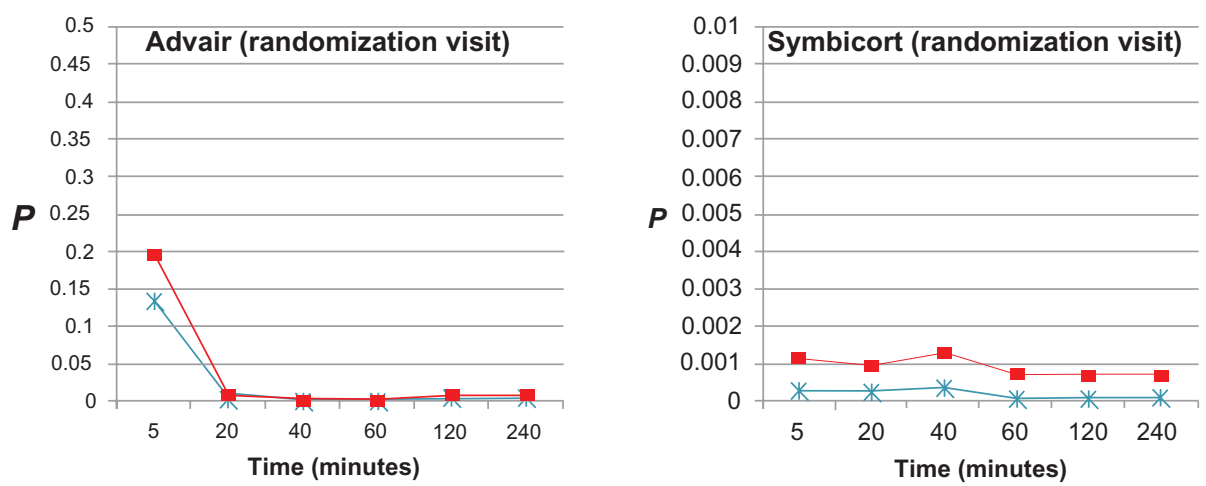

Figure I $t$-test $P$-values of impulse oscillometry parameters (frequency-dependent resistance [R5-R20], *, and reactance [AX], $\mathbf{0}$ ) at each time point after administration of Advair or Symbicort during randomization visits compared to the patients' baseline R5-R20 and AX values $\left(0.204 \mathrm{cmH}_{2} \mathrm{O} / \mathrm{L} / \mathrm{second}\right.$ and I.526 cmH $\mathrm{O}_{2} \mathrm{O} / \mathrm{L}$, respectively, for Advair; $0.259 \mathrm{cmH}_{2} \mathrm{O} / \mathrm{L} /$ second, and $2.332 \mathrm{cmH}_{2} \mathrm{O} / \mathrm{L}$, respectively, for Symbicort) during the same visit $(\mathrm{n}=15$ for each group).

teenagers and young adults, at times comparable to those for Symbicort pMDI $160 / 4.5$. Even mild asthma is primarily a small-airway disease, hence this study's outcome-measures focus on those IOS parameters (R5-R20, $A X$ ) and respiratory system model estimates $\left(R_{p}, C_{p}\right)$ that reflect small-airway mechanics. ${ }^{5,6}$ Note that in general, in all subjects, dosing resulted in lower R5-R20, $A X$, and $R_{p}$ values and higher $C_{p}$ values, consistent with improved small-airway mechanics and therefore reduced airflow obstruction. ${ }^{3}$

Our data indicate that Symbicort acted slightly more quickly than Advair during visit 2 (steroid-naïve condition). This resembles previous studies comparing similar medications, such as Palmqvist et $\mathrm{al}^{2}{ }^{2}$ who studied 30 asthmatic adults (28-73 years old) administered budesonide/formoterol $(160 / 4.5)$ or salmeterol/fluticasone $(50 / 250)$ or placebo using spirometric measurements (forced expiratory volume in 1 second $\left[\mathrm{FEV}_{1}\right]$ ); onset of action, significantly different from placebo, was reported by 3 minutes and by 15 minutes, respectively. Our data also show that R5-R20 and $C_{p}$ were the more sensitive indicators of drug action.

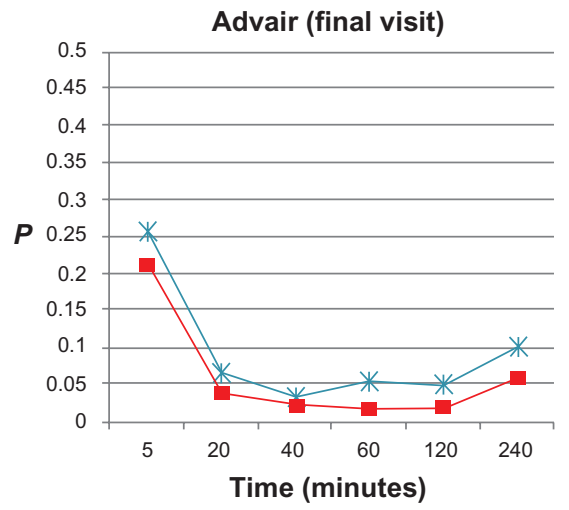

However, after 4 weeks of dosing, the drugs' effects were muted, with Symbicort showing less action than Advair. This is probably due to a $64 \%$ decrease in baseline $A X\left(2.33-0.83 \mathrm{cmH}_{2} \mathrm{O} / \mathrm{L}\right)$ for the Symbicort group over that period, whereas baseline $A X$ decreased only $26 \%$ (1.53-1.13 $\mathrm{cmH}_{2} \mathrm{O} / \mathrm{L}$ ) during the same time-frame in the Advair group, ie, Symbicort produced greater long-term improvement in small-airway mechanics than Advair. Box plots of the individual $A X$ values, grouped by medication, are shown in Figure 5 to illustrate their statistical relationships over time. Note that 60 minutes postdose during the randomization visits is roughly when the two groups (on average) showed the most significant reduction in $A X$, while during the final visits this nadir was reached slightly later, at about 120 minutes.

Similarly, the change in baseline R5-R20, $C_{p}$, and $R_{p}$ between visits for the Symbicort group was 51\% (0.259$\left.0.127 \mathrm{cmH}_{2} \mathrm{O} / \mathrm{L} / \mathrm{s}\right), 101 \%\left(0.0674-0.1355 \mathrm{~L} / \mathrm{cmH}_{2} \mathrm{O}\right)$, and $38 \%\left(0.6891-0.4265 \mathrm{cmH}_{2} \mathrm{O} / \mathrm{L} / \mathrm{s}\right)$, respectively, versus $20 \%$ (0.204-0.164 cmH $\left.\mathrm{cm}_{2} \mathrm{O} / \mathrm{L} / \mathrm{s}\right), 37 \%\left(0.0840-0.1147 \mathrm{~L} / \mathrm{cmH}_{2} \mathrm{O}\right)$,

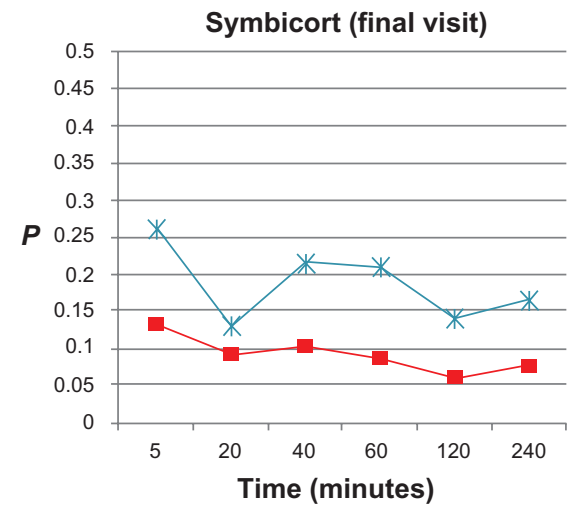

Figure $2 t$-test $P$-values of impulse oscillometry parameters (frequency-dependent resistance [R5-R20], *, and reactance [AX], $\square$ ) at each time point after administration of Advair or Symbicort during final visits compared to the patients' baseline R5-R20 and AX values $\left(0.164 \mathrm{cmH}_{2} \mathrm{O} / \mathrm{L} / \mathrm{second}\right.$ and I.I7I $\mathrm{cmH}_{2} \mathrm{O} / \mathrm{L}$, respectively, for Advair; $0.127 \mathrm{cmH}_{2} \mathrm{O} / \mathrm{L} /$ second and $0.833 \mathrm{cmH}_{2} \mathrm{O} / \mathrm{L}$, respectively, for Symbicort) during the same visit ( $\mathrm{n}=15$ for each group). 

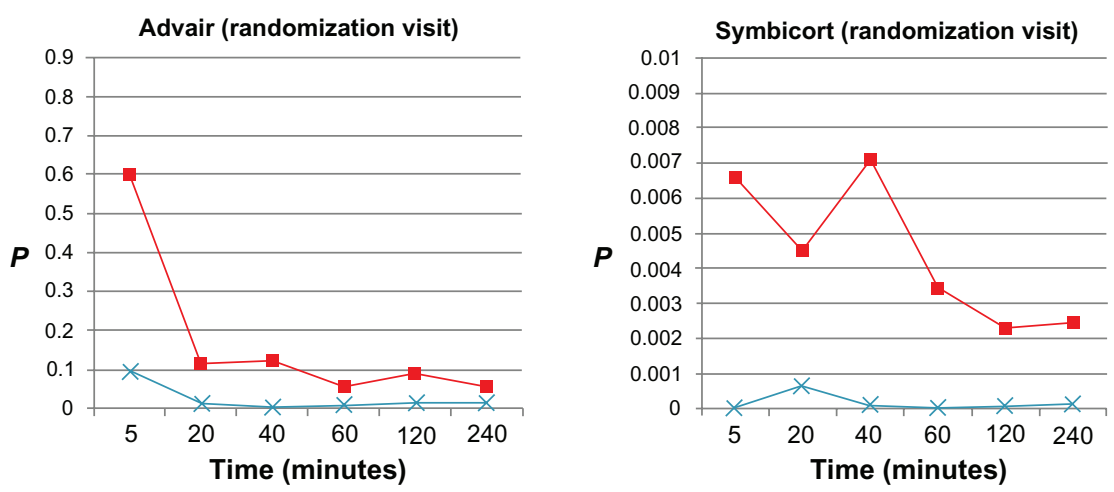

Figure 3 t-test $P$-values of model estimates (peripheral airway resistance $\left[R_{p}\right]$, $\square$; peripheral airway compliance $\left.[C], \times\right)$ at each time point after administration of Advair or Symbicort during randomization visits compared to the patients' baseline $R_{p}$ and $C_{p}$ values $\left(0.547 \mathrm{cmH}_{2} \mathrm{O} / \mathrm{L} / \mathrm{second}\right.$ and $0.084 \mathrm{~L} / \mathrm{cmH}_{2} \mathrm{O}$, respectively, for Advair; $0.689 \mathrm{cmH}_{2} \mathrm{O} / \mathrm{L} /$ second and $0.067 \mathrm{~L} / \mathrm{cmH}_{2} \mathrm{O}$, respectively, for Symbicort) during the same visit ( $\mathrm{n}=15$ for each group).

and $14 \%\left(0.5474-0.4716 \mathrm{cmH}_{2} \mathrm{O} / \mathrm{L} / \mathrm{s}\right)$, respectively, for the Advair group. Figures $6-8$ show box plots of the individual R5-R20, $C_{p}$, and $R_{p}$ values, respectively, grouped by medication, to illustrate their statistical relationships over time.

Comparing the various parameters over time, the other findings can be summarized as follows:

- During the randomization visits, Symbicort produced greater bronchodilation at 5 minutes than Advair. Since baseline $A X=2.33 \mathrm{cmH}_{2} \mathrm{O} / \mathrm{L}$ and $\mathrm{R} 5-\mathrm{R} 20=0.259 \mathrm{cmH}_{2} \mathrm{O} / \mathrm{L} / \mathrm{second}$ for the Symbicort group, and baseline $A X=1.53 \mathrm{cmH}_{2} \mathrm{O} / \mathrm{L}$ and $\mathrm{R} 5-\mathrm{R} 20=0.204 \mathrm{cmH}_{2} \mathrm{O} / \mathrm{L} /$ second for the Advair group, the Symbicort group had slightly worse lung function than the Advair group, but at 5 minutes post-study drug, values were $A X=0.643 \mathrm{cmH}_{2} \mathrm{O} / \mathrm{L}$ and R5-R20 $=0.113 \mathrm{cmH}_{2} \mathrm{O} / \mathrm{L} /$ second for the Symbicort group, and $A X=1.12 \mathrm{cmH}_{2} \mathrm{O} / \mathrm{L}$ and $\mathrm{R} 5-\mathrm{R} 20=0.159 \mathrm{cmH}_{2} \mathrm{O} / \mathrm{L} /$ second for the Advair group. The same implications can be gathered from the $R_{p}$ and $C_{p}$ values at baseline for the Symbicort group (0.689 $\mathrm{cmH}_{2} \mathrm{O} / \mathrm{L} /$ second, $0.0674 \mathrm{~L} / \mathrm{cmH}_{2} \mathrm{O}$ ) and Advair group ( $0.547 \mathrm{cmH}_{2} \mathrm{O} / \mathrm{L} /$ second, $\left.0.0840 \mathrm{~L} / \mathrm{cmH}_{2} \mathrm{O}\right)$, and at 5 minutes post-study drug for the Symbicort group (0.397 $\mathrm{cmH}_{2} \mathrm{O} / \mathrm{L} /$ second, $\left.0.1340 \mathrm{~L} / \mathrm{cmH}_{2} \mathrm{O}\right)$ and Advair group $\left(0.503 \mathrm{cmH}_{2} \mathrm{O} / \mathrm{L} /\right.$ second, $\left.0.1138 \mathrm{~L} / \mathrm{cmH}_{2} \mathrm{O}\right)$.

- During the final visits, Symbicort produced lesser bronchodilation at 5 minutes than Advair. Since baseline $A X=0.83 \mathrm{cmH}_{2} \mathrm{O} / \mathrm{L}$ and $\mathrm{R} 5-\mathrm{R} 20=0.127 \mathrm{cmH}_{2} \mathrm{O} / \mathrm{L} /$ second for the Symbicort group, and baseline $A X=1.13 \mathrm{cmH}_{2} \mathrm{O} / \mathrm{L}$ and $\mathrm{R} 5-\mathrm{R} 20=0.164 \mathrm{cmH}_{2} \mathrm{O} / \mathrm{L} /$ second for the Advair group, the Symbicort group's lung function had become better than the Advair group's lung function after 4 weeks of treatment. So the Symbicort group had less room to respond to bronchodilator/anti-inflammatory action. This was corroborated by the smaller baseline $R_{p}$ and larger baseline $C_{p}$ for the Symbicort group $\left(0.426 \mathrm{cmH}_{2} \mathrm{O} / \mathrm{L} /\right.$ second, $0.1355 \mathrm{~L} / \mathrm{cmH}_{2} \mathrm{O}$ ) compared to the Advair group $\left(0.472 \mathrm{cmH}_{2} \mathrm{O} / \mathrm{L} / \mathrm{second}, 0.1147 \mathrm{~L} / \mathrm{cmH}_{2} \mathrm{O}\right)$.

- For the randomization visits, change in R5-R20 was greater than change in $A X$ at all-time points for both drugs. However, for the final visits, this order was reversed.

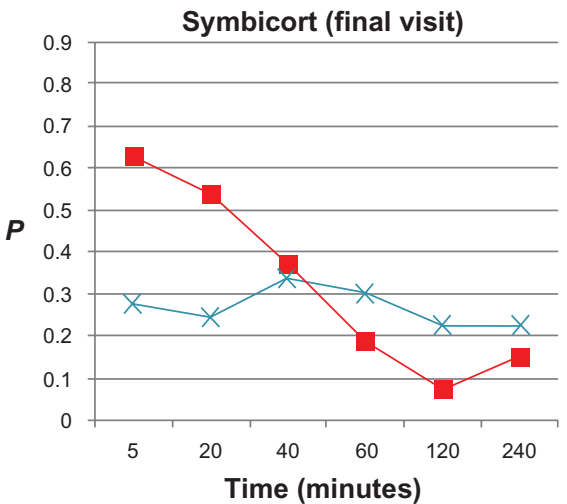

Figure $4 t$-test $P$-values of model estimates (peripheral airway resistance $\left[R_{p}\right]$, $\square$; peripheral airway compliance $\left[C_{p}\right], \times$ ) at each time point after administration of $A d v a i r$ or Symbicort during final visits compared to the patients' baseline $R_{p}$ and $C_{p}$ values $\left(0.472 \mathrm{cmH}_{2} \mathrm{O} / \mathrm{L} /\right.$ second and $0.115 \mathrm{~L} / \mathrm{cmH}_{2} \mathrm{O}$, respectively, for Advair; $0.426 \mathrm{cmH} H_{2} \mathrm{O} / \mathrm{L} / \mathrm{second}$ and $0.136 \mathrm{~L} / \mathrm{cmH}_{2} \mathrm{O}$, respectively, for Symbicort) during the same visit ( $\mathrm{n}=15$ for each group). 
A

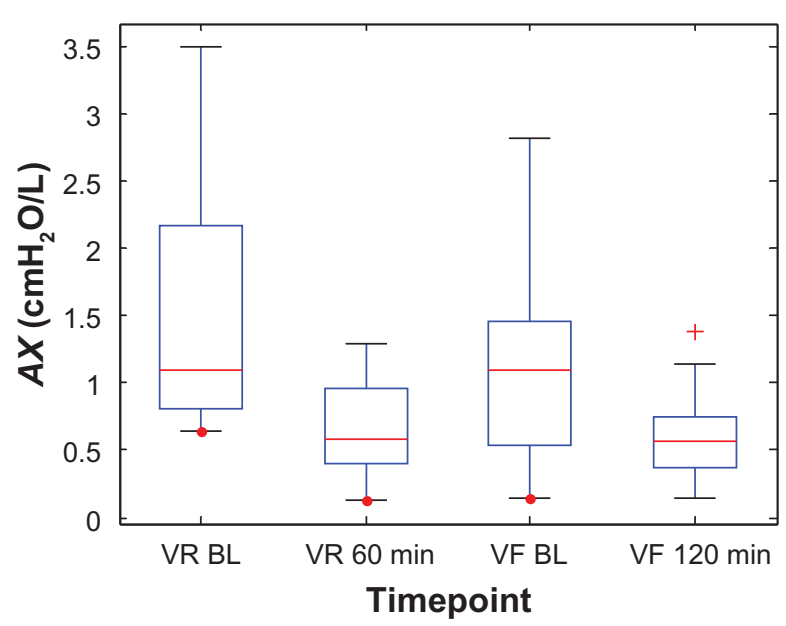

B

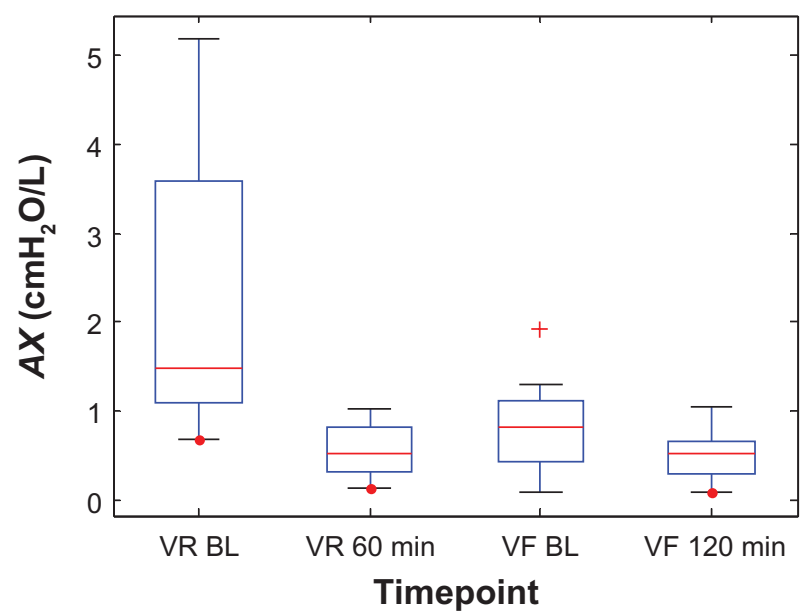

Figure 5 Box plots of the individual impulse oscillometry frequency-dependent reactance $(A X)$ values at two time points each during the randomization visits (VR) and the final visits (VF) for (A) the Advair group and (B) the Symbicort group.

Abbreviation: BL, baseline.

Hence, long-term ICS/LABA use appears to fundamentally modify lung mechanics, resulting in less asynchronous behavior (improved time constants).

- For the randomization visits, the change in $C_{p}$ was greater than the change in $R_{p}$ at all-time points for both drugs. However, for the final visits, this order was reversed, and the change in $R_{p}$ was greater than the change in $C_{p}$ at all-time points for Advair and after 40 minutes for Symbicort. It seems plausible to attribute these changes to the anti-inflammatory effects of inhaled corticosteroids, particularly on the small-airway walls' compliance. This suggests that the respiratory system model provides additional information regarding small-airway mechanics that is not conveyed by either $\mathrm{R} 5-\mathrm{R} 20$ or $A X$, although
A

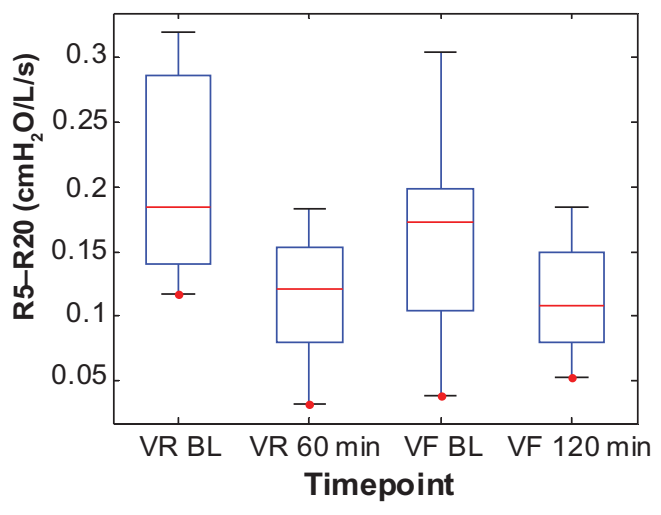

B

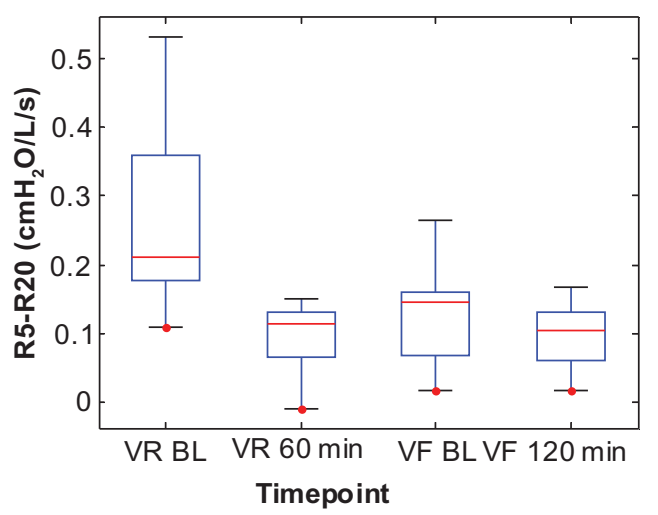

Figure 6 Box plots of the individual impulse oscillometry frequency-dependent resistance (R5-R20) values at two time points each during the randomization visits (VR) and the final visits (VF) for (A) the Advair group and (B) the Symbicort group. Abbreviation: BL, baseline.

A

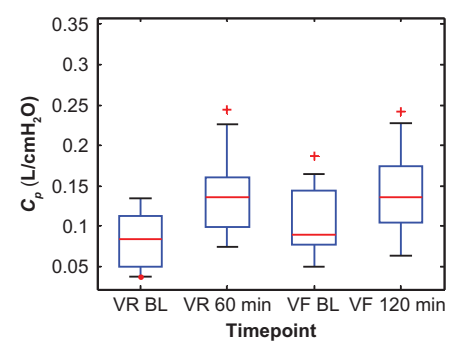

B

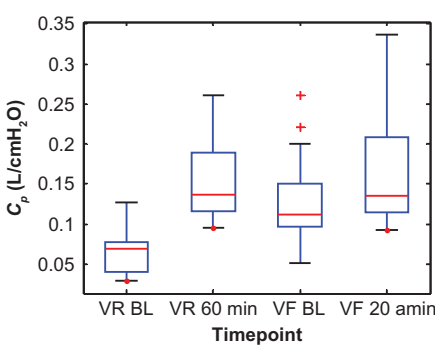

Figure 7 Box plots of the individual peripheral airway compliance $\left(C_{p}\right)$ values at two time points each during the randomization visits (VR) and the final visits (VF) for (A) the Advair group and (B) the Symbicort group.

Abbreviation: BL, baseline. 

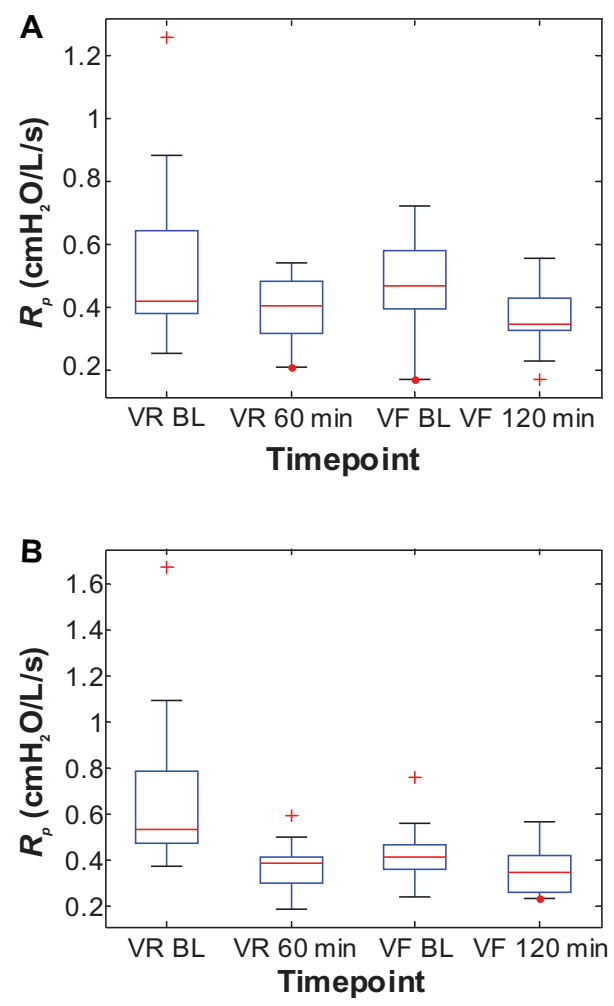

Figure 8 Box plots of the individual peripheral airway resistance $\left(R_{\mathrm{p}}\right)$ values at two time points each during the randomization visits (VR) and the final visits (VF) for (A) the Advair group and (B) the Symbicort group.

Abbreviation: BL, baseline.

$R_{p}$ and $C_{p}$ seem less sensitive for detecting changes in small-airway function. Moreover, $R_{p}$ and $C_{p}$ exhibit different aspects of the physiological effects of these drugs, especially Symbicort, as seen in Figures 3 and 4.

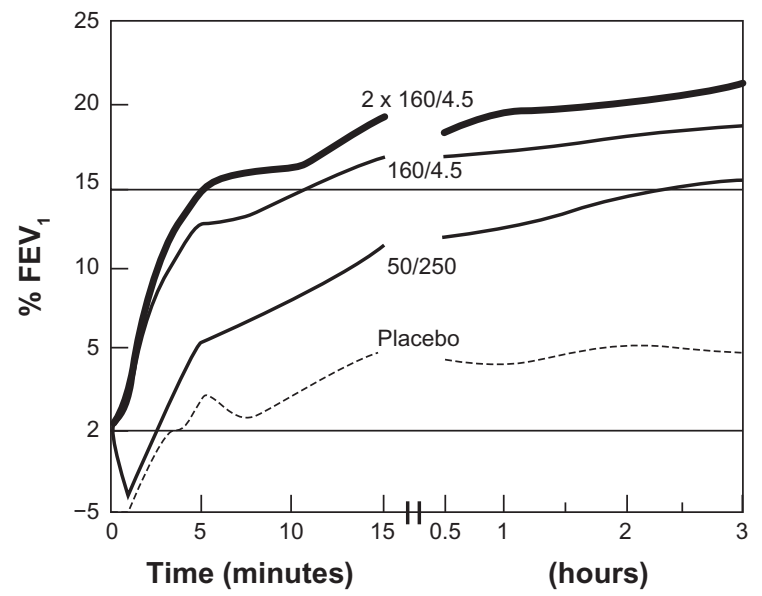

Figure 9 Mean forced expiratory volume in I second $\left(\mathrm{FEV}_{1}\right)$ during the first 180 minutes after inhalation of budesonide/formoterol (pressurized metered-dose inhaler [PMDI] $2 \times 160 / 4.5 \mathrm{mg}$ ), salmeterol/fluticasone (pMDI $2 \times 25 / 250 \mathrm{mg}$ ), salbutamol $(2 \times 100 \mathrm{mg})$, or placebo (percentage increase from predrug value). Copyright () 200I, Elsevier. Palmqvist M, Arvidsson P, Beckman O, Peterson S, Lötvall J. Onset of bronchodilation of budesonide/formoterol vs salmeterol/ fluticasone in single inhalers. Pulm Pharmacol Ther. 2001;14(I):29-34. ${ }^{2}$
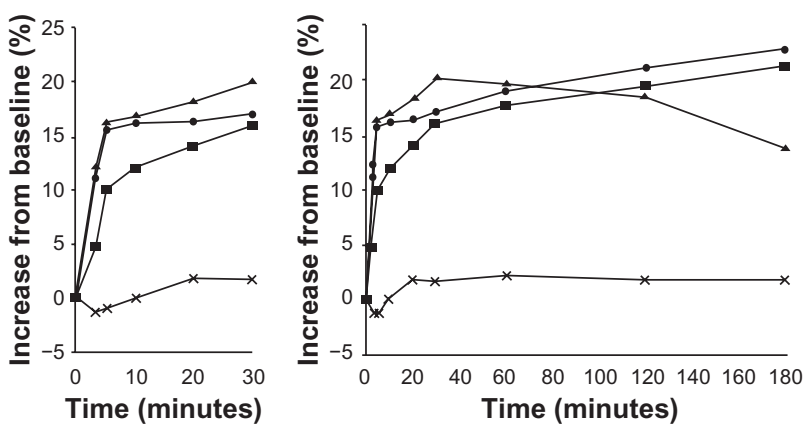

Figure 10 Percent change in forced expiratory volume in I second (FEV $)_{1}$ up to 15 minutes and 3 hours with the combination of budesonide/formoterol (one or two inhalations) (160/4.5 mg) compared with the combination salmeterol/fluticasone (50/250 mg) and placebo. Reprinted from Lindberg et al, ${ }^{10}$ with permission from John Wiley and Sons.

- It appears that Symbicort produces a biphasic effect on lung mechanics, ie, a quick-phase effect from about 5 to 30 minutes postdose, and a slow-phase effect from about 50 minutes to over 240 minutes postdose. This can be observed in both visits' results for $A X$ and R5-R20 (Figures 1 and 2), and for $R_{p}$ and $C_{p}$ (Figures 3 and 4). Its cause is uncertain, although one may hypothesize that formoterol has quite different pharmacodynamics than budesonide. Previous studies investigating Symbicort's onset and/or duration of action ${ }^{2,7-11}$ were consulted. Data presented by Palmqvist et $\mathrm{al}^{2}$ for asthmatic adults and by Lindberg et $a{ }^{10}$ for chronic obstructive pulmonary disease in adults (Figures 9 and 10) show an inflection in the change from baseline $\mathrm{FEV}_{1}$ value occurring between 5 and $10 \mathrm{~min}$ utes and between 10 and 20 minutes, respectively, although Figure 9 also shows an inflection in that time range for the placebo group. Although neither paper suggested a possible biphasic action, their results and ours indicate that the parameters' inflections are due not to random variations but some real physiological phenomenon.

\section{Conclusion}

Advair HFA MDI 115/21 produced a significant response almost as early as Symbicort pMDI 160/4.5 after a single dose in 12- to 45-year-old mild asthmatics, as determined by IOS parameters and lung-model estimates: between 5 and 20 minutes versus less than 5 minutes, respectively. This finding was consistent whether one considered R5-R20 or $A X$ or $C_{p}$ or $R_{p}$, which are all associated with peripheral (small) airway mechanics.

Moreover, after 4 weeks of dosing, there was evidence that both ICS/LABA combinations had produced significant sustained improvement in peripheral airway parameters. 
This improvement resulted in diminished predose-to-postdose differences, with Symbicort improving steady-state lung function slightly more than Advair. It was somewhat surprising that there was no further improvement in small-airway parameters when comparing single to steady-state dosing. These findings could still have real-world clinical importance in that the sustained amelioration of small-airway dysfunction (decreased obstruction and improved compliance) noted in these mild asthmatic subjects could lead to meaningful clinical benefits based on the documented association between small-airway dysfunction and asthma control. ${ }^{3}$

Finally, a biphasic effect of Symbicort on lung function was observed that has heretofore been unnoted. Since earlier studies' data provide additional evidence that this is a real phenomenon, further investigation as to its basis and implications seems warranted.

\section{Acknowledgments}

RM initiated this research, acquired funding for it, and supervised the patient screening and data collection. BD performed the data analysis and drafted the various versions of the manuscript, which RM reviewed and approved. $\mathrm{KS}$ assisted with the model-parameter estimations and data analysis, and produced the summary tables and graphs under BD's supervision. Finally, we thank Michael D Goldman, MD (in memoriam) of the Geffen School of Medicine, University of California, Los Angeles, for his input on this study's protocol.

\section{Disclosure}

This study was supported by an unrestricted grant from GlaxoSmithKline. The authors have no other conflicts of interest to disclose.

\section{References}

1. Menendez R, Goldman MD, Diong BM, Nazeran H. Impulse oscillometry (IOS) measures effects of short and long acting betaagonists (SABA, LABA) on lung mechanics in 2-5 year old children with asthma. J Allergy Clin Immunol. 2008;121(2 Suppl 1):S211.

2. Palmqvist M, Arvidsson P, Beckman O, Peterson S, Lötvall J. Onset of bronchodilation of budesonide/formoterol vs salmeterol/fluticasone in single inhalers. Pulm Pharmacol Ther. 2001;14(1):29-34.

3. van der Wiel E, ten Hacken NHT, Postma DS, van den Berge M. Small-airways dysfunction associates with respiratory symptoms and clinical features of asthma: a systematic review. JAllergy Clin Immunol. 2013;131(3):646-657.

4. Oostveen E, MacLeod D, Lorino H, et al. The forced oscillation technique in clinical practice: methodology, recommendations and future developments. Eur Respir J. 2003;22(6):1026-1041.

5. Smith H, Reinhold P, Goldman M. Forced oscillation technique and impulse oscillometry. Eur Respir Mon. 2005;31(5):72-105.

6. Diong B, Rajagiri A, Goldman M, Nazeran H. The augmented RIC model of the human respiratory system. Med Biol Eng Comput. 2009;47(4):395-404.

7. Cazzola M, Santus P, Di Marco F, et al. Onset of action of formoterol/ budesonide in single inhaler vs formoterol in patients with COPD. Pulm Pharmacol Ther. 2004;17(3):121-125.

8. Masoli M, Williams M, Weatherall M, Beasley R. The $24 \mathrm{~h}$ duration of bronchodilator action of the budesonide/formoterol combination inhaler. Respir Med. 2006;100(1):20-25.

9. Lötvall J, Langley S, Woodcock A. Inhaled steroid/long-acting beta 2 agonist combination products provide 24 hours improvement in lung function in adult asthmatic patients. Respir Res. Aug 18, 2006;7:110.

10. Lindberg A, Szalai Z, Pullerits T, Radeczky E. Fast onset of effect of budesonide/formoterol versus salmeterol/fluticasone and salbutamol in patients with chronic obstructive pulmonary disease and reversible airway obstruction. Respirology. 2007;12(5):732-739.

11. Kaiser H, Parasuraman B, Boggs R, Miller CJ, Leidy NK, O'Dowd L. Onset of effect of budesonide and formoterol administered via one pressurized metered-dose inhaler in patients with asthma previously treated with inhaled corticosteroids. Ann Allergy Asthma Immunol. 2008;101(3):295-303.
Journal of Asthma and Allergy

\section{Publish your work in this journal}

The Journal of Asthma and Allergy is an international, peer-reviewed open-access journal publishing original research, reports, editorials and commentaries on the following topics: Asthma; Pulmonary physiology; Asthma related clinical health; Clinical immunology and the immunological basis of disease; Pharmacological interventions and

\section{Dovepress}

new therapies. Issues of patient safety and quality of care will also be considered. The manuscript management system is completely online and includes a very quick and fair peer-review system, which is all easy to use. Visit http://www.dovepress.com/testimonials.php to read real quotes from published authors. 